\title{
Gestational weight gain and group prenatal care: a systematic review and meta-analysis
}

\author{
Michelle A. Kominiarek ${ }^{{ }^{*}}$ (D) Adam K. Lewkowitz ${ }^{2}$, Ebony Carter $^{2}$, Susan A. Fowler ${ }^{3}$ and Melissa Simon ${ }^{4}$
}

\begin{abstract}
Background: Group visits for chronic medical conditions in non-pregnant populations have demonstrated successful outcomes including greater weight loss compared to individual visits for weight management. It is plausible that group prenatal care can similarly assist women in meeting gestational weight gain goals. The purpose of this study was to evaluate the effect of group vs. traditional prenatal care on gestational weight gain.

Methods: A keyword search of Medline, Embase, Scopus, Cochrane Database of Systematic Reviews, Database of Abstracts of Reviews of Effects, Cochrane Central Register of Controlled Trials, clinicaltrials.gov, and Google Scholar was performed up to April 2017. Studies were included if they compared gestational weight gain in a group prenatal care setting to traditional prenatal care in either randomized controlled trials, cohort, or case-control studies. The primary and secondary outcomes were excessive and adequate gestational weight gain according to the Institute of Medicine guidelines. Heterogeneity was assessed with the $\mathrm{Q}$ test and $\mathrm{I}^{2}$ statistic. Pooled relative risks (RRs) and confidence intervals $(\mathrm{Cl})$ were reported with random-effects models from the randomized controlled trials (RCT) and cohort studies.

Results: One RCT, one secondary analysis of an RCT, one study with "random assignment", and twelve cohort studies met the inclusion criteria for a total of 13,779 subjects. Thirteen studies used the CenteringPregnancy model, defined by 10 sessions that emphasize goal setting and self-monitoring. Studies targeted specific populations such as adolescents, African-Americans, Hispanics, active-duty military or their spouses, and women with obesity or gestational diabetes. There were no significant differences in excessive [7 studies: pooled rates 47\% (1806/ $3582)$ vs. $43 \%$ (3839/8521), RR $1.09,95 \% \mathrm{Cl} 0.97-1.23$ ] or adequate gestational weight gain [6 studies: pooled rates $31 \%(798 / 2875)$ vs. 30\% (1410/5187), RR 0.92, 95\% Cl 0.79-1.08] in group and traditional prenatal care among the nine studies that reported categorical gestational weight gain outcomes in the meta-analysis.

Conclusions: Group prenatal care was not associated with excessive or adequate gestational weight gain in the meta-analysis. Since outcomes were overall inconsistent, we propose that prenatal care models (e.g., group vs. traditional) should be evaluated in a more rigorous fashion with respect to gestational weight gain.
\end{abstract}

Keywords: Group prenatal care, Gestational weight gain, Perinatal outcomes

\section{Introduction}

Since pregnancy is a time when women may be motivated to improve their health behaviors, it is often considered the optimal time to intervene on health behaviors such as eating habits and physical activity so that gestational weight gain goals are met and perinatal

\footnotetext{
* Correspondence: mkominia@nm.org

${ }^{1}$ Department of Obstetrics and Gynecology, Division of Maternal-Fetal Medicine, Northwestern University Feinberg School of Medicine, 250 East Superior Street, Suite 05-2175, Chicago, IL 60611, USA

Full list of author information is available at the end of the article
}

outcomes optimized [1]. Excessive gestational weight gain is positively correlated with postpartum weight retention and is a predictor of long-term, higher body mass index in women and their offspring [2-4]. Proposed long-term metabolic consequences of excessive gestational weight gain for women include type 2 diabetes, cardiovascular disease, and metabolic syndrome [5]. Trends in increasing adult weights and excessive gestational weight gain in the United States over the past two decades have shifted the focus of gestational weight

(c) The Author(s). 2019 Open Access This article is distributed under the terms of the Creative Commons Attribution 4.0 International License (http://creativecommons.org/licenses/by/4.0/), which permits unrestricted use, distribution, and reproduction in any medium, provided you give appropriate credit to the original author(s) and the source, provide a link to the Creative Commons license, and indicate if changes were made. The Creative Commons Public Domain Dedication waiver (http://creativecommons.org/publicdomain/zero/1.0/) applies to the data made available in this article, unless otherwise stated. 
gain counseling so as to avoid excessive gestational weight gain. Nonetheless, according to a national study, nearly $50 \%$ of all women exceeded these goals in 2010 2011 [6]. As such, meeting gestational weight gain goals is important for women and their offsprings' long-term health.

Although diet and exercise interventions can reduce excessive gestational weight gain by $20 \%$, some critiques of these trials are that they failed to address the relationship between psychosocial factors (e.g., depression, body image, and social support) and gestational weight gain $[7,8]$. Furthermore, the majority of the interventions were performed in individual sessions with 1:1 healthcare professional-participant settings. Group visits for weight management in non-pregnant populations have demonstrated successful outcomes including greater weight loss compared to usual care $[9,10]$. It is plausible that group prenatal care can similarly assist women in meeting gestational weight gain goals. Evidence suggests that compared to those receiving traditional individual prenatal care, women who receive group prenatal care have lower rates of preterm birth and cesarean delivery and higher rates of breastfeeding and knowledge and satisfaction with prenatal care. However, these findings have not been consistent and the mechanism for the possible improvement in outcomes is unknown [11-14]. Sheeder et al. conducted a review of group prenatal care literature and cited only two studies about gestational weight gain with one reporting increased mean weight gain in group participants without regard to the pre-pregnancy body mass index and the other reporting no differences in responses to a question about whether women made health behavior changes "to gain an appropriate amount of weight" at the end of the study between group and non-group participants [15].

\section{Objective}

Given the importance of meeting gestational weight gain goals for a woman's long term health, the limitations of health behavior interventions to promote meeting gestational weight gain goals, and the limited evidence for group prenatal care and gestational weight gain outcomes, the objective of this study was to systematically review the literature to compare gestational weight gain in group and traditional prenatal care and evaluate group prenatal care for having excessive or adequate gestational weight gain with a meta-analysis.

\section{Methods}

Eligibility criteria, information sources, search strategy

The published literature was searched using strategies created by a medical librarian (S.A.F.) for the concepts of group prenatal care and gestational weight gain.(Additional file 1) These strategies were established using a combination of standardized terms and key words, and were implemented in Medline 1946-, Embase 1947-, Scopus 1823-, Cochrane Database of Systematic Reviews, Database of Abstracts of Reviews of Effects, Cochrane Central Register of Controlled Trials, clinicaltrials.gov 2000-, and Google Scholar. All searches were completed in April 2017. No database limits such as language or years were applied. All literature database and Google Scholar results were exported to EndNote.

\section{Study selection}

Studies were included if they described a group prenatal care setting (exposure) and reported gestational weight gain (outcome), either as means or by adequacy of gestational weight gain categories, per the Institute of Medicine guidelines. We included original research studies such as randomized controlled trials or observational studies (retrospective cohort, case-control) with a comparison group of traditional or individual prenatal care. We excluded case reports, case series, review articles, studies without comparison groups, and studies published in languages other than English.

\section{Data extraction}

The first and second authors (M.A.K., A.K.L.) screened the titles and abstracts and then retrieved the full-text articles if they appeared relevant or if there was uncertainty regarding the screening criteria. Full-text articles and abstracts (when full-text was not available) were independently reviewed for inclusion and exclusion criteria by the same authors (M.A.K., A.K.L.), who have expertise in prenatal care. Consensus was achieved between these two authors for included articles. For each article that met the inclusion criteria, study characteristics, participant demographics (age, parity, race-ethnicity, body mass index), study-specific inclusion criteria, setting, gestational weight gain definition, and outcome data relevant to gestational weight gain were abstracted and summarized. Specifications for body mass index (pre-pregnancy vs. first prenatal care visit measurement vs. not recorded) and gestational weight gain (difference between the pre-pregnancy vs. first prenatal visit and final prenatal visit vs. delivery weight vs. not recorded) were also abstracted. Categorization of gestational weight gain was defined by the 2009 Institute of Medicine guidelines per pre-pregnancy body mass index category (28-40 pounds for $<18.5 \mathrm{~kg} / \mathrm{m}^{2}, 25-35$ pounds for $18.5-24.9$ $\mathrm{kg} / \mathrm{m}^{2}, 15-25$ pounds for $25.0-29.9 \mathrm{~kg} / \mathrm{m}^{2}$, and $11-20$ pounds for $\geq 30 \mathrm{~kg} / \mathrm{m}^{2}$ ), if applicable, with the terms inadequate, adequate, or excessive [16]. We also noted whether or not gestational age at delivery was accounted for in the total gestational weight gain measurement and whether or not the total number of group or traditional prenatal care visits attended was reported. 


\section{Study quality assessment}

The quality of each study was assessed with the Down's checklist which contains 27 questions pertaining to threats to validity including reporting, external validity, internal validity, confounding or selection bias, and power [17]. The Down's checklist is validated for both randomized and observational studies. The maximum possible score was 28 , indicating the highest quality study. We considered studies receiving the majority of the points available in at least four of the five categories of threats as high quality with scoring similar to O'Connor et al. (24-28 excellent, 19-23 good, 14-18 fair, and $<14$ poor) [18]. Both M.A.K. and A.K.L. completed the quality rating form for each article, with E.C. resolving any discrepancies in scoring to achieve a final consensus score.

\section{Data synthesis}

The primary outcome was the occurrence of excessive gestational weight gain as determined by body mass index and the Institute of Medicine guidelines, but we also evaluated the occurrence of adequate gestational weight gain. Data were analyzed with STATA (version 14, College Station, TX) using the METAN software package. Study heterogeneity was assessed with Cochran's $\mathrm{Q}$ and Higgins $\mathrm{I}^{2}$ tests. Conservative significance thresholds of $P<0.1$ for the Q tests or $\mathrm{I}^{2}>30 \%$, were used to test heterogeneity [19]. Relative risks (RR) were calculated with raw data from each study with a 95\% confidence interval (CI) using raw data from each study. The DerSimonian-Laird random-effects models were used to pool data, regardless of whether there was evidence of statistical heterogeneity. RR for each categorical outcome were plotted graphically as forest plots. A sensitivity analysis by study quality with those studies at the top tertile of Down's scores was also performed to assess the effect of these factors on our estimates. Publication bias was assessed graphically using funnel plots.

Institutional review board approval was not necessary for this study of de-identified data available in the public domain through prior publications. This systematic review was registered in PROSPERO on February 1, 2017 (\#CRD42017056296). The Preferred Reporting Items for Systematic Reviews and Meta-Analyses (PRISMA) guidelines were followed for all aspects of reporting [20].

\section{Results}

\section{Study selection}

The initial electronic search found 631 results. One hundred twenty six duplicates were accurately identified and removed with the automatic duplicate finder in EndNote. An additional 47 duplicate citations were identified by hand and removed for a total of 458 unique citations.(Fig. 1) Titles and abstracts for each citation were reviewed and 64 full-text articles (or abstracts if full-text was not available) were screened according to the inclusion and exclusion criteria. Reference lists of excluded articles were reviewed to identify other relevant articles and no additional studies were found. A total of 49 studies were removed for no reported gestational weight gain outcomes, no group prenatal care arm, no control group, and/or review article only.

\section{Study characteristics}

Fifteen studies met inclusion criteria, including one randomized controlled trial (RCT), one secondary analysis of an RCT, one study with "random assignment" and 12 cohort studies for a total of 13,779 subjects, 4243 (31\%) in group and $9536(69 \%)$ in traditional prenatal care. Table 1 describes the characteristics of studies meeting inclusion criteria. CenteringPregnancy ${ }^{\mathrm{Tm}}$ group prenatal care was the most common prenatal care model used in included studies $(n=13)$. In CenteringPregnancy ${ }^{\mathrm{Tm}}$, women receive prenatal visits, build relationships with other women, and gain knowledge and skills in pregnancy and childbirth in 10 sessions [21]. During the first group session, nutrition, including caloric requirements and macronutrient recommendations, is typically discussed. Women also receive a notebook that includes a food diary and a body mass index table labeled with the categories of normal, overweight, obese, and extreme obesity. Additionally, women chart their own weight over time in the notebooks. The curriculum overall encourages goal setting, including diet, exercise, and weight gain. None of the studies using the CenteringPregnancy ${ }^{\text {in }}$ model in this systematic review reported whether or not the content was specifically adapted to target weight gain. The two non-CenteringPregnancy ${ }^{\mathrm{mm}}$ models are described as follows. Harden et al. performed a mixed methods study on group-based lifestyle sessions within prenatal care with six-1 h group visits consisting of safe group exercises, nutrition education and demonstrations, and group activities such as goal setting [22]. Mazzoni et al. described a group prenatal care intervention consisting of four sessions for women with gestational diabetes [23]. Several of the other included studies describe an intervention that was targeted at specific populations such as adolescents [24, 25], African-Americans [26], Hispanics [27], active-duty military or their spouses $[28,29]$, women with obesity $[22]$ and women with gestational diabetes $[23,30]$.

\section{Risk of bias of included studies}

The validated Downs scale for randomized and observational studies was used to assess the quality of the studies with scores ranging from 9 to 19 with a median value of 12 (interquartile range 12-16). (Table 2) Of the 15 studies selected for this systematic review, 


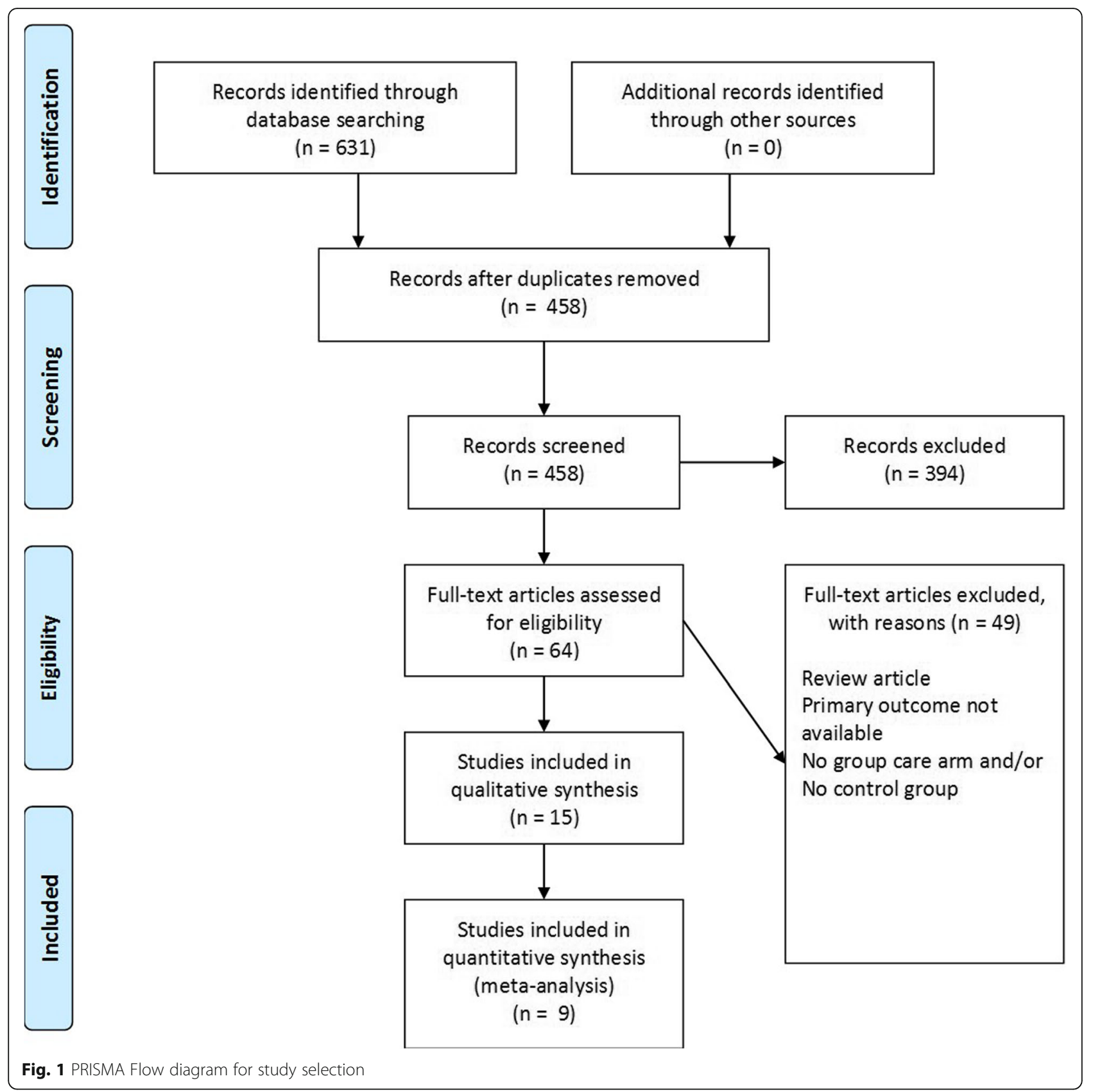

6 were not included in the meta-analysis because they reported only a mean gestational weight gain without regard to the participants' pre-pregnancy body mass index $[22,23,26,29-31]$. Two of these studies also did not report the variance of the gestational weight gain measure $[29,31]$. Without a pre-pregnancy weight value, there is limited clinical interpretation for a mean gestational weight gain. Four of the six studies also did not specify if Institute of Medicine guidelines were used to counsel participants on overall gestational weight gain goals [23, 24, 30, 31].

\section{Synthesis of results}

Table 3 describes the sample size, weight gain outcomes, how the control group was chosen if applicable, any adjustments for gestational age in the analysis, total number of prenatal visits, and provider types for all 15 studies. The six studies not included in the meta-analysis are summarized as follows [22, 23, 26, 29$31]$. Of note, only two studies had gestational weight gain as a primary outcome [22, 29] and only one study adapted the content of care to target weight gain [22]. A retrospective cohort study based in a clinic which served 


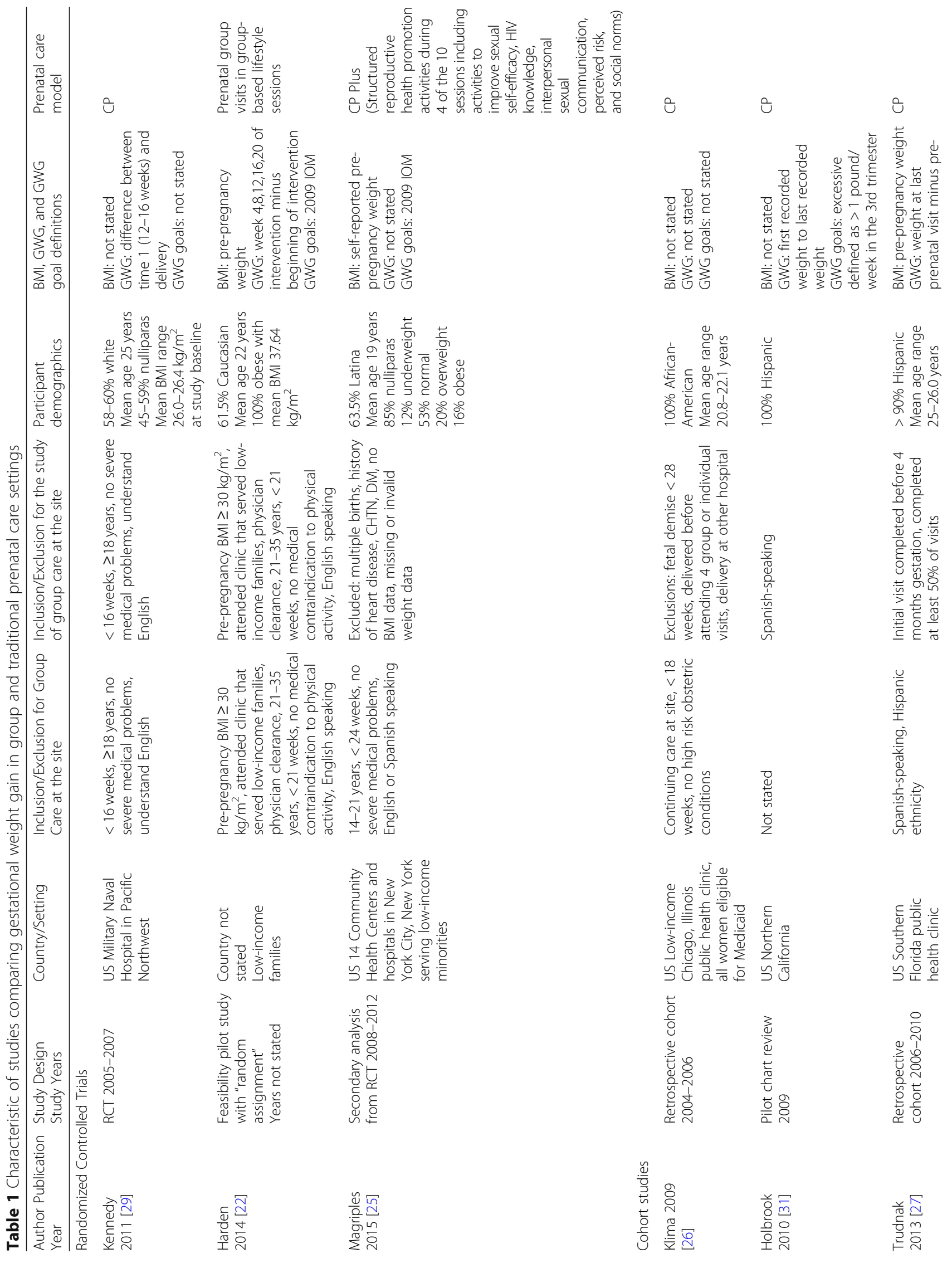




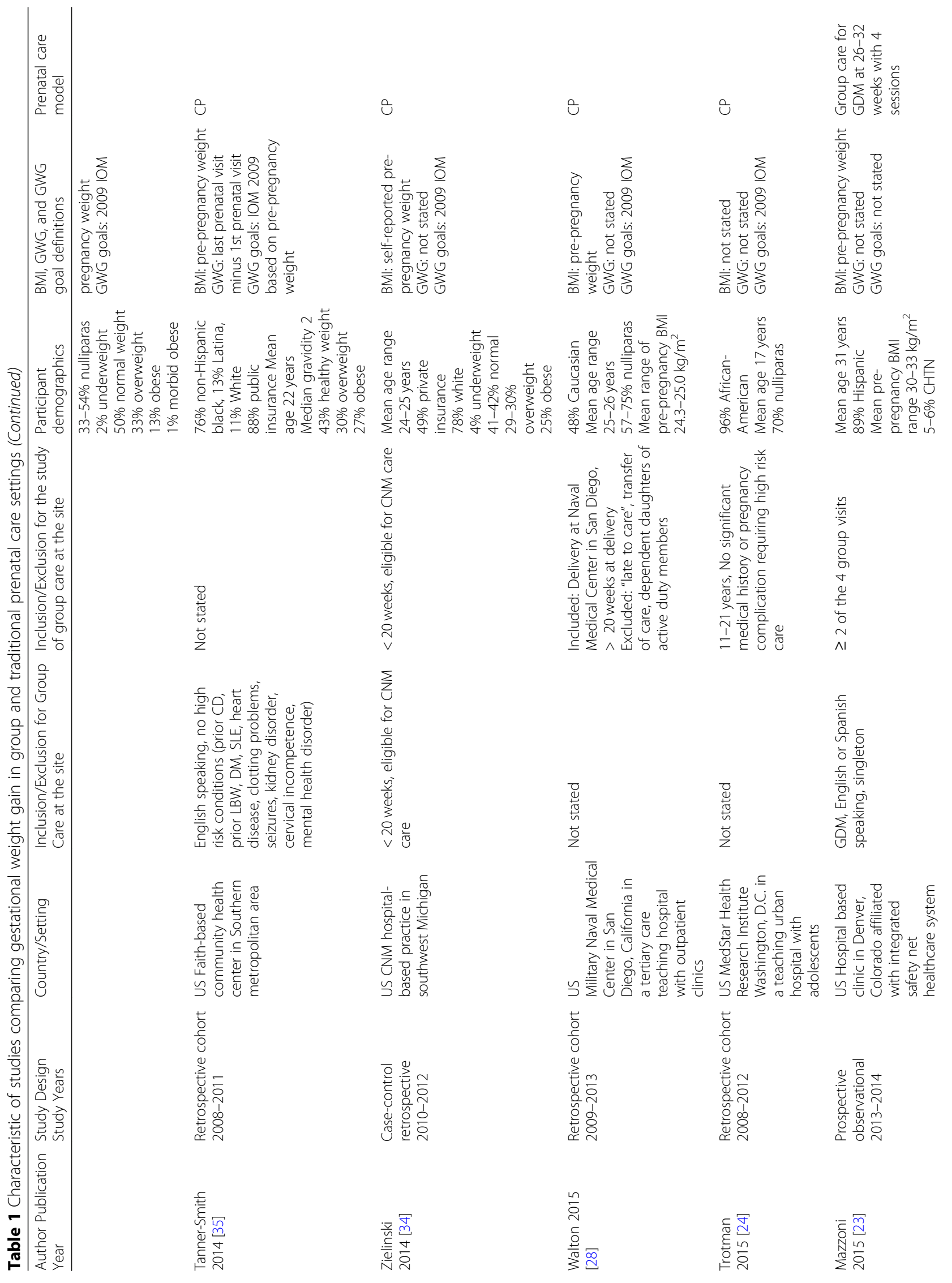




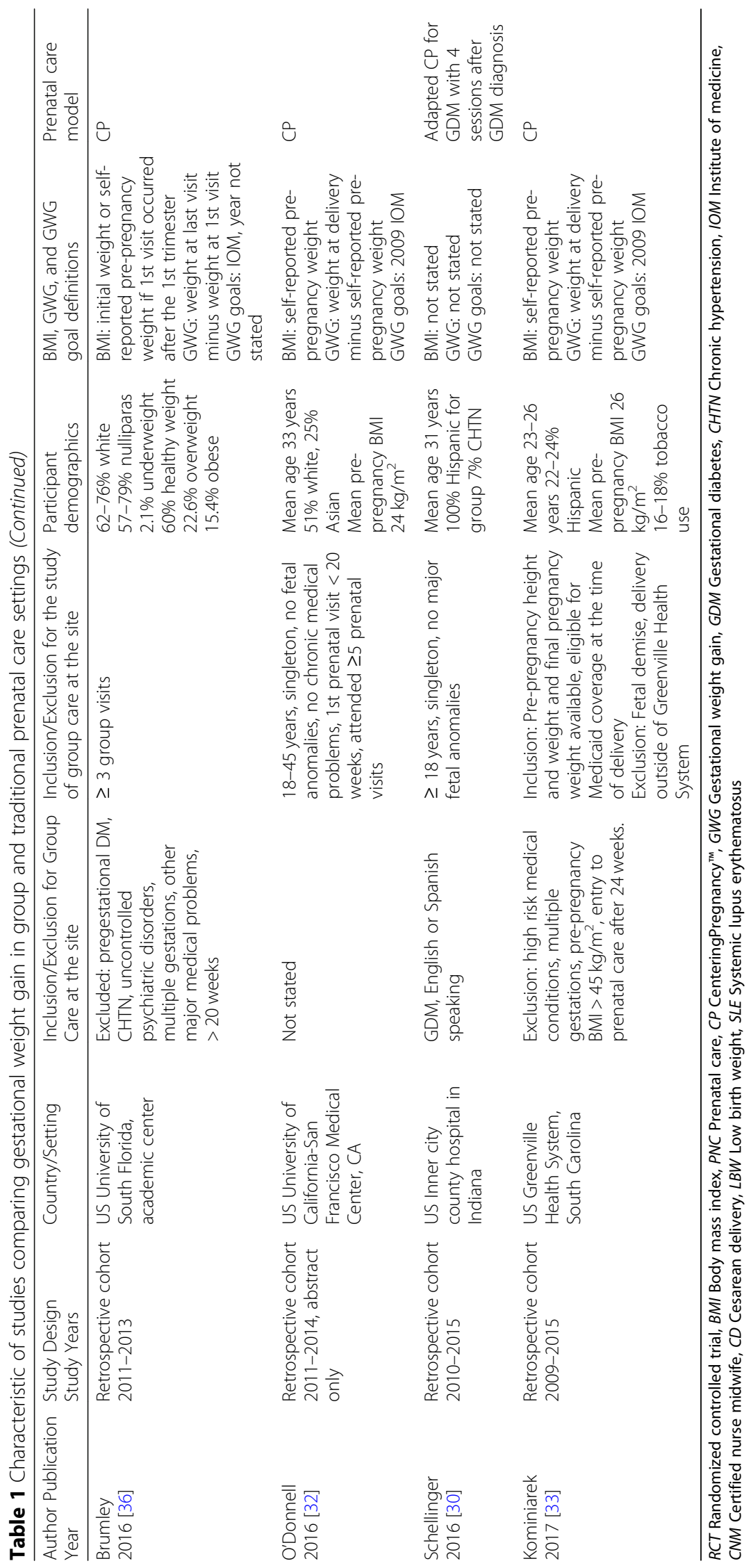


Table 2 Quality Score for 15 Studies According to Threats to Validity and Overall Score

\begin{tabular}{|c|c|c|c|c|c|c|}
\hline \multirow[t]{2}{*}{ Author, Year } & \multicolumn{5}{|c|}{ Threats to validity $^{a}$} & \multirow[t]{2}{*}{ Tota } \\
\hline & Reporting (11) & External validity (3) & Internal validity (7) & Confounding or selection bias (6) & Power (1) & \\
\hline \multicolumn{7}{|l|}{ Randomized trials } \\
\hline Kennedy 2011 [29] & 9 & 2 & 3 & 5 & 0 & 19 \\
\hline Harden 2014 [22] & 5 & 0 & 2 & 2 & 0 & 9 \\
\hline Magriples 2015 [25] & 9 & 1 & 2 & 5 & 0 & 17 \\
\hline \multicolumn{7}{|l|}{ Cohort studies } \\
\hline Klima 2009 [26] & 6 & 1 & 3 & 2 & 0 & 12 \\
\hline Holbrook 2010 [31] & 3 & 1 & 3 & 2 & 0 & 9 \\
\hline Trudnak 2013 [27] & 7 & 1 & 4 & 2 & 0 & 14 \\
\hline Tanner-Smith 2014 [35] & 8 & 1 & 4 & 3 & 0 & 16 \\
\hline Zielinski 2014 [34] & 8 & 2 & 0 & 2 & 0 & 12 \\
\hline Walton 2015 [28] & 7 & 2 & 1 & 2 & 0 & 12 \\
\hline Trotman 2015 [24] & 6 & 2 & 2 & 2 & 0 & 12 \\
\hline Mazzoni 2015 [23] & 8 & 1 & 3 & 2 & 0 & 14 \\
\hline Brumley 2016 [36] & 7 & 0 & 3 & 2 & 0 & 12 \\
\hline O'Donnell 2016 [32] & 8 & 1 & 4 & 3 & 0 & 16 \\
\hline Schellinger 2016 [30] & 5 & 1 & 2 & 2 & 0 & 10 \\
\hline Kominiarek 2017 [33] & 9 & 1 & 4 & 3 & 0 & 17 \\
\hline
\end{tabular}

${ }^{a}$ Numbers in parenthesis represent maximum score for the category

predominantly low-income minority women was the first to report on gestational weight gain in CenteringPregnancy $^{\text {mis }}$ from 2004 to 2006. This study found increased mean gestational weight gain in women in CenteringPregnancy $^{\text {Tim }}(n=61)$ compared to women in traditional prenatal care $(n=207)(32.2$ pounds vs. 28.5 pounds $p<0.05$ ), yet the pre-pregnancy body mass index was not reported so the proportion of women who met the gestational weight gain goals is not known [26]. Similarly, Holbrook evaluated gestational weight gain among 100 Spanish-speaking women receiving group (based on CenteringPregnancy ${ }^{\mathrm{TM}}$ model) or traditional prenatal care in 2009 in the U.S via a "pilot chart review"; however, pre-pregnancy body mass and statistical comparisons for gestational weight gain were not provided [31]. A RCT in a military setting from 2005 to 2007 found no difference in mean gestational weight gain between CenteringPregnancy ${ }^{\mathrm{Tm}}$, but the authors also did not specify the pregnancy body mass index [29].

Harden et al. reported on group-based lifestyle sessions within prenatal care in two "feasibility pilot studies with random assignment" that aimed to limit excessive gestational weight gain [22]. In the first study, women with a pre-pregnancy body mass index $\geq 30 \mathrm{~kg} / \mathrm{m}^{2}$ were randomly assigned to either standard of care $(n=8)$ or the intervention $(n=8)$. Women in the control group gained significantly more weight at the 20th week of the program compared to those in the intervention $(8.6 \pm 3.9 \mathrm{~kg}$ vs. 5.3 $\pm 5.3 \mathrm{~kg}, p<0.01)$. The investigators received positive feedback from both providers and patients about the program, but because the participants suggested that the medical appointments be conducted separately from the group-based lifestyle sessions, they conducted a follow-up study whereby women of all body mass index categories were randomized to either the group-based lifestyle sessions $(n=28)$ or the control group $(n=23)$ which consisted of individual goal setting, didactic nutritional education, and a $30 \mathrm{~min}$ standard exercise class. The group-based lifestyle sessions were similar to the initial study and also included discussion of barriers and potential solutions to reaching goals, sharing of baked snacks from the provided recipe book, exchanging of telephone numbers, and group exercises such as a walking track, dance, and prenatal yoga. Because the follow-up study occurred separately from prenatal care visits, the information was not included in the meta-analysis. Furthermore, $19(37 \%)$ of all participants were missing gestational weight gain, so the finding that $36 \%$ in the group-based lifestyle sessions vs. $13 \%$ in the control group met the gestational weight gain goals $(p=0.06)$ needs to be interpreted with caution [22].

The two other studies not included in the meta-analysis specifically targeted women with gestational diabetes. Mazzoni et al. aimed to compare the progression of gestational diabetes (from diet to medically-treated) in group and traditional prenatal care in a prospective observational study in the U.S [23]. Participants started the program between 26 and 32 weeks gestation for a total of four 


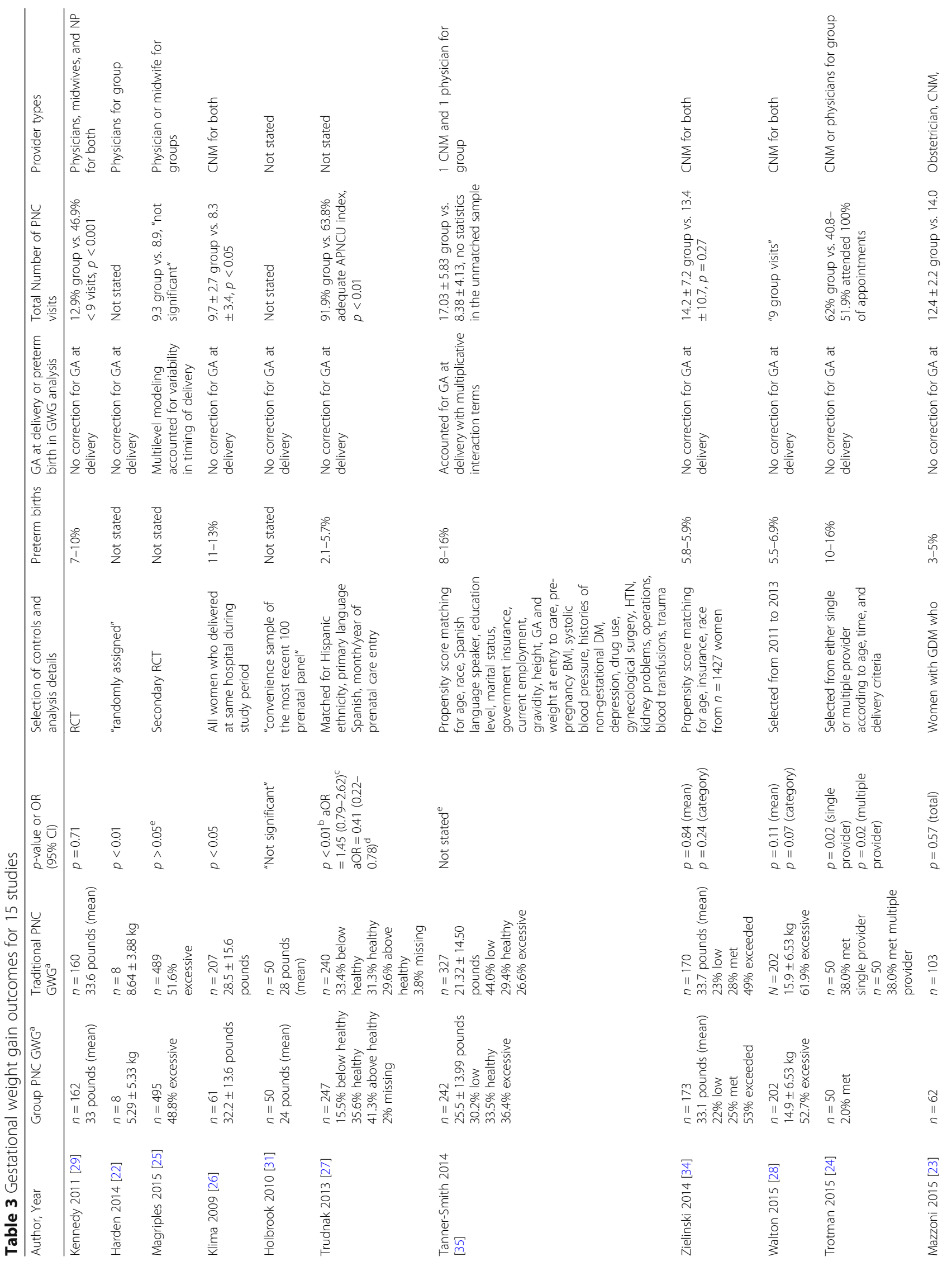




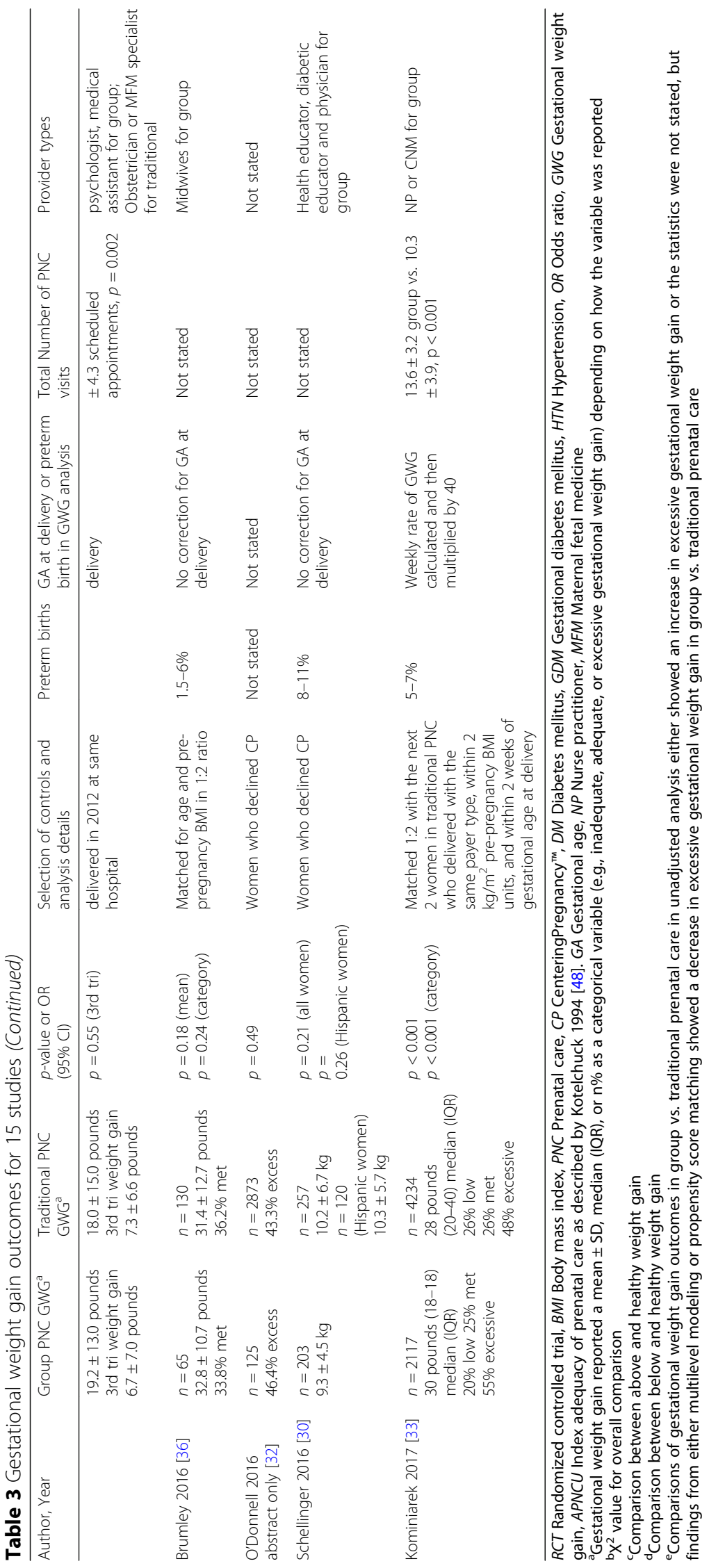


sessions which covered topics such as meal planning, glucose log review, mindful eating, and lifelong diabetes prevention. Mean gestational weight gain was similar in both group $(19.2 \pm 13.0$ pounds $)$ and traditional $(18.0 \pm 15.0$ pounds) prenatal care, $p=0.57$. Lastly, Schellinger et al. developed an adapted CenteringPregnancy ${ }^{\mathrm{m}}$ model in Spanish only for Hispanic women with gestational diabetes. The CenteringPregnancy ${ }^{\text {Tix }}$ model was adapted to a total of four visits in the 3rd trimester with facilitated discussions on blood sugar monitoring, nutrition, and exercise [30]. Gestational weight gain, a secondary outcome in their retrospective cohort study, was compared to women in traditional prenatal care with gestational diabetes, but only mean values were reported $(9.3 \pm 4.5$ pounds vs. 10.2 \pm 6.7 pounds, $p=0.26$ ) [30].

Of the nine studies in the meta-analysis, all used the CenteringPregnancy ${ }^{\text {mi }}$ model and three studies had both excessive and adequate gestational weight gain outcomes. Seven studies reported the primary outcome of excessive gestational weight gain (Fig. 2) [25, 27, 28, 3235]. Overall, there was no significant difference in the occurrence of excessive gestational weight gain [7 studies: pooled rates $47 \%(1806 / 3582)$ vs. $43 \%(3839 / 8521)$, RR 1.09, 95\% CI 0.97-1.23] in group and traditional prenatal care. Given the low overall quality values (fair to poor), we separately evaluated studies in the top tertile quality scores based on the range and distribution of scores and found that excessive gestational weight gain was higher in group compared to traditional care [pooled rates $45 \%(1608 / 3207)$ vs. $39 \%(3631 / 8149)$, RR 1.15, 95\% CI 1.01-1.30] (Fig. 3). There was significant heterogeneity between the studies that evaluated excessive gestational weight gain, as demonstrated by $\mathrm{I}^{2}$ values of $74.2 \%(p=0.001)$ and $68.0 \%(p=0.014)$ (Figs. 2 and $3)$. Six studies reported the secondary outcome of adequate gestational weight gain (Fig. 4) [24, 27, 33-36]. There also was no significant difference in adequate gestational weight gain [6 studies: pooled rates 31\% (798/ $2875)$ vs. $30 \%$ (1410/5187), RR 0.92, 95\% CI 0.79-1.08] in group and traditional prenatal care. There also was significant heterogeneity between the studies that evaluated adequate gestational weight gain, as demonstrated by an $\mathrm{I}^{2}$ value of $58.6 \%(p=0.03)$ (Fig. 4$)$. There appeared to be symmetry with the funnel plot and therefore publication bias was minimal (Fig. 5).

\section{Discussion \\ Main findings}

This systematic review found 15 studies of poor to fair quality with 13,779 subjects meeting the criteria of comparing gestational weight gain according to a group vs. traditional prenatal care model, with the number of studies further limited for the meta-analysis of excessive $(n=$ $7)$ and adequate $(n=6)$ gestational weight gain [22-36].

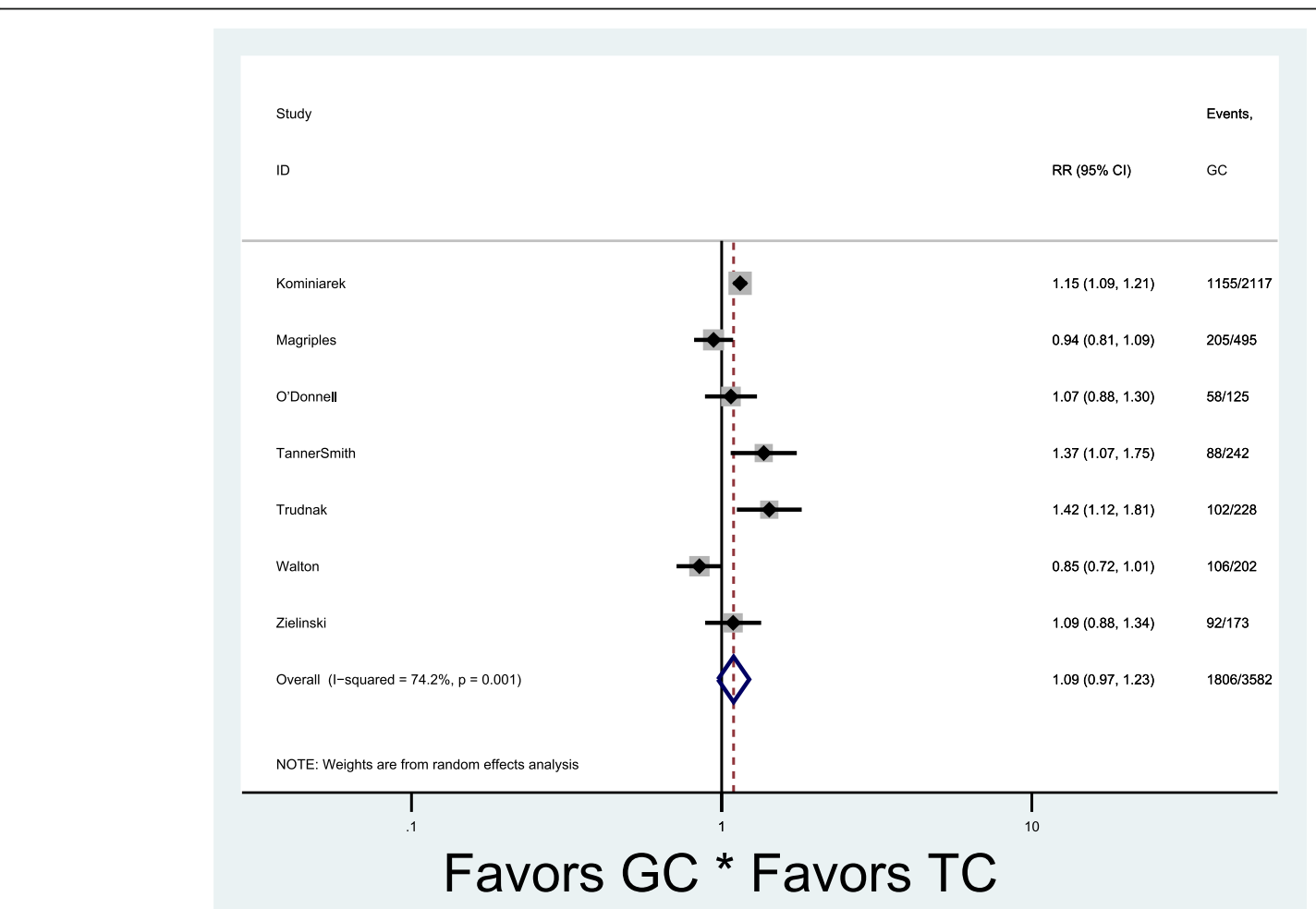

Fig. 2 Forest plot for excessive gestational weight gain in group vs. traditional prenatal care. RR risk ratio $\mathrm{Cl}$ confidence interval TC traditional care GC group care 


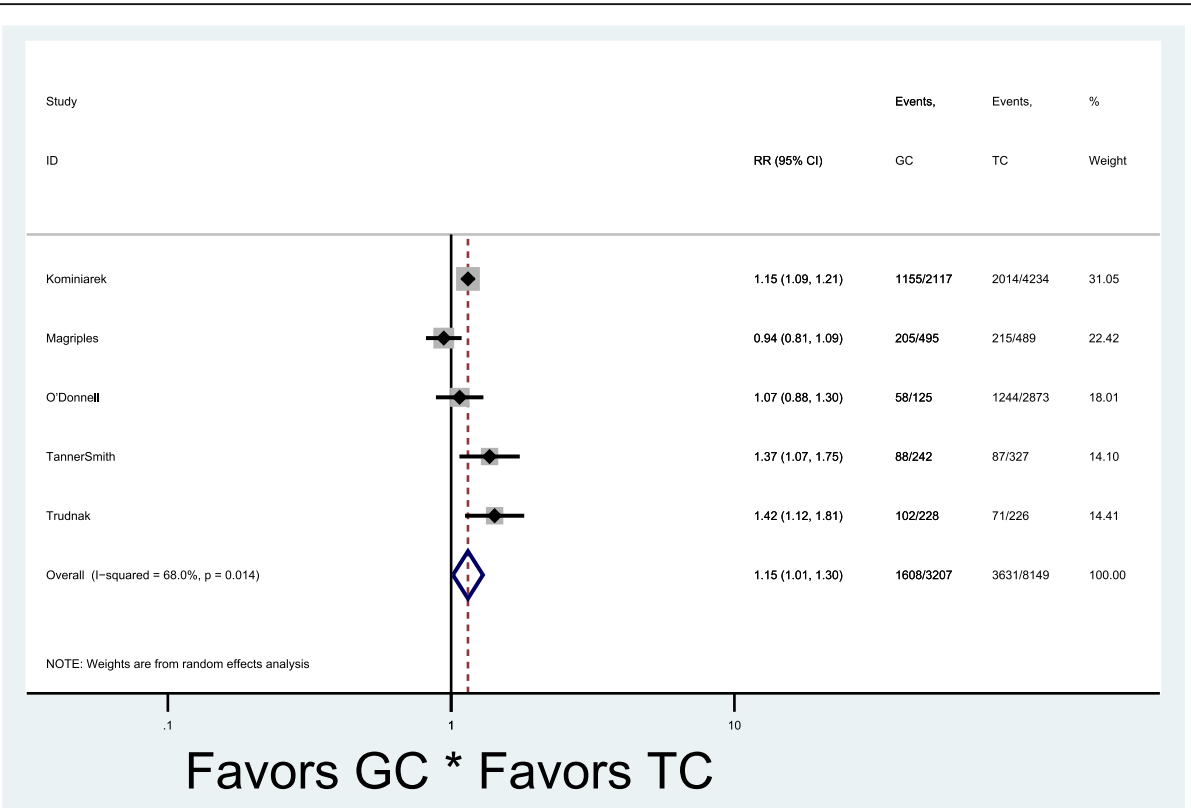

Fig. 3 Forest plot for excessive gestational weight gain in group vs. traditional prenatal care in high quality studies. RR risk ratio $\mathrm{Cl}$ confidence interval TC traditional care GC group care

We found that group prenatal care was not associated with excessive or adequate gestational weight gain except in the highest quality studies in the meta-analysis, which had a very modest but increased risk for excessive gestational weight gain for group prenatal care. Of the studies included in this meta-analysis, Tanner-Smith et al. and Magriples et al. both found reductions in excessive gestational weight gain in adjusted analysis (propensity score matching for 20 maternal characteristics and multi-level modeling, respectively) for CenteringPregnancy ${ }^{\text {Tw }}$ women, which suggests other confounding factors such as race-ethnicity, gravidity, pre-pregnancy body mass index, and gestational age at the entry to prenatal care are responsible for the relationship between prenatal care model and gestational weight gain $[25,35]$. These two studies used the 2009 Institute of Medicine definitions for body

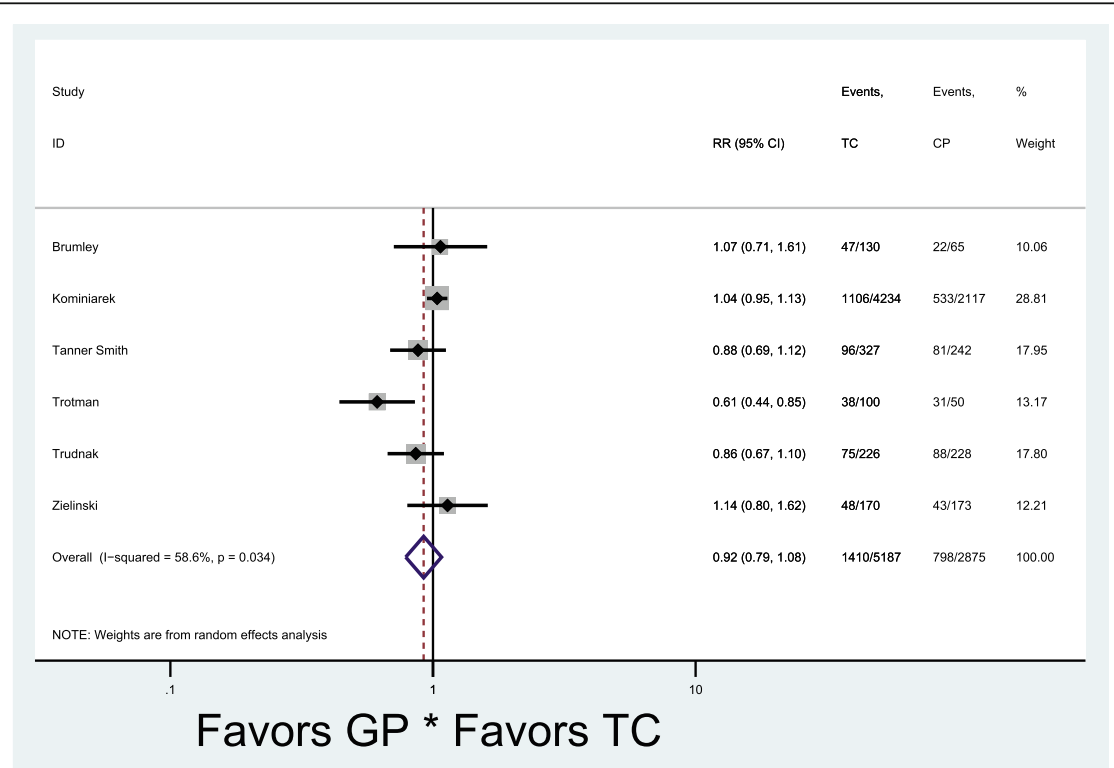

Fig. 4 Forest plot for adequate gestational weight gain in group vs. traditional prenatal care. RR risk ratio; Cl confidence interval TC traditional care GC group care. Of note, individual studies referred to gestational weight gain as "normal", "healthy", or "met goals", but for the purposes of this analysis, they were grouped into the category of "adequate" gestational weight gain. 


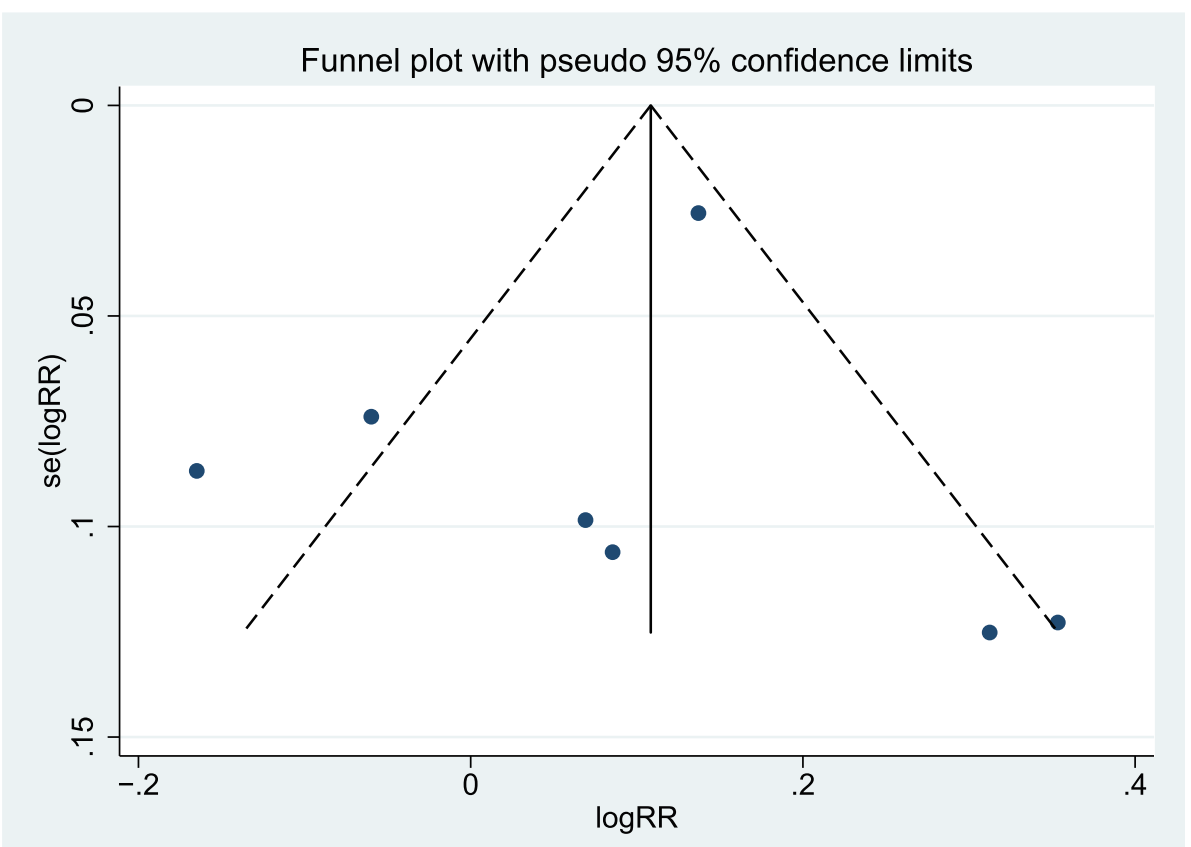

Fig. 5 Funnel plot with 95\% confidence limits for the effect of group vs. traditional prenatal care on excessive gestational weight gain. RR risk ratio

mass index and gestational weight gain, directly compared CenteringPregnancy ${ }^{\mathrm{mm}}$ and traditional prenatal care, and had a greater total number of subjects $(n=569$ and 984, respectively) than most studies. Conversely, Kominiarek et al. found a direct association between excessive gestational weight gain and group prenatal care, primarily among normal and overweight women, in a study of 6351 women [33].

\section{Strengths and limitations}

Our study has several strengths. First, we used a predesigned protocol with a comprehensive search strategy conducted by a trained, expert research librarian, and two authors independently extracted data, which reduced bias. Second, we used a pre-specified sensitivity analyses according to the risk of bias assessment. Third, we pooled data from studies using a more conservative random-effects model to account for clinical heterogeneity between studies. Finally, because gestational weight gain is an important construct that impacts maternal and offspring outcomes and there are many variations of group prenatal care across the U.S., this systematic review and meta-analysis sheds some light on the state of the inconsistent evidence for group prenatal care as it relates to this important outcome. We acknowledge several limitations to this systematic review and meta-analysis. The majority of the studies were secondary analyses from RCT or retrospective cohort studies where the risk for selection bias and confounding is greater especially since women typically opt-in or self-select for group prenatal care. For example, women in group prenatal care are typically younger, of lower parity, and more frequently minorities of lower socioeconomic status, all of which can positively or negatively influence gestational weight gain [37]. The selection of women from traditional prenatal care varied among the studies and included matching for age, delivery date, ethnicity, and/or pre-pregnancy body mass index, matching for women who declined group prenatal care, and matching according to a propensity score. We noted a greater number of nulliparas $[24,27,28,36]$ and minority women [24] in group care compared to traditional prenatal care in some of the studies included in this systematic review. In summary, these factors, including participant demographics (age, race-ethnicity, geographical location), participant characteristics (age, body mass index, gestational diabetes), and intervention dose (length and number of visits, gestational age at entry) may explain the heterogeneity we observed in the meta-analysis.

We were not able to evaluate the content (i.e., how much emphasis placed on gestational weight gain goals) or dose (i.e., number of group sessions attended) of the group prenatal care program or the experience or effectiveness of the group prenatal care facilitator. The primary outcome, gestational weight gain, was not well defined in several studies and also varied from a difference between a first and last prenatal visit to a difference between the start and end of the intervention. Other limitations of these individual studies for a meta-analysis 
include lack of pre-pregnancy body mass index information, differing statistical approaches, and small cohort sizes.

\section{Comparison with existing literature}

With respect to weight management, highly effective components of weight management interventions include calorie and physical activity goals, meal replacements, daily self-weighing and monitoring of food intake, behavior therapy, and frequent provider-patient contact [13]. Several of these components are already integral elements of group prenatal care such as CenteringPregnancy ${ }^{\text {Tx }}$. In general, group health care visits have the potential to improve the effectiveness and efficiency of health care because multiple patients are seen in the same clinical setting by a multidisciplinary team consisting of physicians, nurses, dieticians, and other health educators [38, 39]. Weight management is just one example where group care models are practiced among others including diabetes, smoking cessation, geriatrics, and osteoarthritis [40-42].

Social support in the context of group meetings with either peers or self-identified family and friends has been studied in weight management interventions that have highly effective components. A systematic review of five RCT with a group intervention found improved weight change within 1 year for the participants in the group compared to usual care [weighted mean difference - 1.4 $\mathrm{kg}(-2.7 /-0.1 \mathrm{~kg})]$ with a greater effect seen when a financial incentive was incorporated [weighted mean difference $-2.8 \mathrm{~kg}(-5.4 /-0.2 \mathrm{~kg})]$ and when the groups were led by psychologists as compared to nutritionists [9]. Furthermore, an adapted version of the Diabetes Prevention Program showed that participants in either large ( $\geq 16$ members) or small groups $(<16$ members), still had weight loss outcomes $(5.1-5.8 \mathrm{~kg})$ similar to the goals of the initial study (7\% weight loss from initial weight) [43]. Commercial weight loss programs promote the concept of social support as critical to achieving goals $[44,45]$. It has been proposed that support from attending meetings [e.g., Weight Watchers ${ }^{\circ}$ and TOPS Club, Inc. (Taking Off Pounds Sensibly)] enhances feelings of control and confidence and consequently group-based interventions result in greater weight loss compared to individual care $[9,10,44-46]$. For example, in a prospective, 2-year clinical trial that randomly assigned participants to either Weight Watchers ${ }^{\oplus}$ meetings or the self-help method, those assigned to Weight Watchers ${ }^{\oplus}$ meetings lost and kept off significantly more weight [44]. However, findings regarding social support and weight loss are mixed as another meta-analysis of 21 studies concluded that couples programs were effective in short-term weight loss, but not in long-term weight loss maintenance [47]. Given that social support is cited as a successful element in weight management programs in non-pregnant populations and the social support element that accompanies many group prenatal care models such as CenteringPregnancy ${ }^{\mathrm{Tm}}$, it is reasonable to evaluate group prenatal care models regarding their effectiveness in changing health behaviors and achieving gestational weight gain goals.

\section{Conclusions and implications}

Interventions to prevent excessive gestational weight gain are potentially most effective when they parallel effective behavioral lifestyle programs in non-pregnant populations [13]. As such, further research is needed to determine: (1) how social support influences gestational weight gain in health behavior interventions especially in groups that may vary by race-ethnicity and other maternal characteristics, (2) if adaptations to group care are needed to emphasize gestational weight gain goals and its accompanying adverse perinatal and long-term maternal outcomes such as diabetes and cardiovascular disease especially since we found increases in gestational weight gain in group prenatal care for the highest quality studies, and (3) how best to incorporate the prenatal care into the health behavior intervention so that providers can effectively communicate health risks and goals. These are important concepts because so few studies have been able to demonstrate that health behavior interventions improve gestational weight gain and other health outcomes. In conclusion, gestational weight gain for women in group prenatal care has inconsistent findings, but overall we found no differences in gestational weight gain outcomes in group compared to traditional prenatal care. We propose that prenatal care models (e.g., group vs. traditional) should be evaluated in a more rigorous fashion by including more RCT that clearly define and primarily evaluate gestational weight gain outcomes.

\section{Additional file}

Additional file 1: Search strategy for article selection for the systematic review. This file contains the information that the librarian (S.A.F.) used to complete the article searches for the systematic review. (DOCX $14 \mathrm{~kb}$ )

\section{Abbreviations \\ Cl: Confidence intervals; RCT: Randomized controlled trials; RR: Relative risks; TOPS: Taking Off Pounds Sensibly}

\section{Acknowledgements}

Not applicable.

\section{Funding}

This study was supported by Grant Number K23HD076010 from the Eunice Kennedy Shriver National Institute of Child Health \& Human Development of the National Institutes of Health (Michelle A. Kominiarek) and Grant \#74250 from the Robert Wood Johnson Foundation (Ebony Carter). The funder had no role in the design of the study, collection, analysis, and interpretation of data, or in writing the manuscript. 


\section{Availability of data and materials}

All data generated or analyzed during this study are included in this published article and its supplementary information file.

\section{Authors' contributions}

MAK, AKL, EC, and MS formulated the research questions and designed the study protocol. MAK and AKL screened the eligible abstracts, reviewed the full-texts of the articles, and came to agreement on inclusion and bias assessment. MAK, AKL, and EC synthesized the study findings. SF wrote the search strategies and ran the searches. All authors reviewed drafts of the manuscripts and approved the final manuscript prior to submission.

\section{Ethics approval and consent to participate}

Institutional review board approval was not necessary for this study of de-identified data available in the public domain through prior publications.

\section{Consent for publication}

Not applicable.

\section{Competing interests}

The authors declare that they have no competing interests.

\section{Publisher's Note}

Springer Nature remains neutral with regard to jurisdictional claims in published maps and institutional affiliations.

\section{Author details}

'Department of Obstetrics and Gynecology, Division of Maternal-Fetal Medicine, Northwestern University Feinberg School of Medicine, 250 East Superior Street, Suite 05-2175, Chicago, IL 60611, USA. ²Department of Obstetrics and Gynecology, Division of Maternal-Fetal Medicine, Washington University School of Medicine, St. Louis, MO, USA. ${ }^{3}$ Brown School Library, Washington University in St. Louis, St. Louis, MO, USA. ${ }^{4}$ Department of Obstetrics and Gynecology, Northwestern University Feinberg School of Medicine, Chicago, IL, USA.

Received: 26 October 2017 Accepted: 12 December 2018

Published online: 09 January 2019

\section{References}

1. Phelan S. Pregnancy: a "teachable moment" for weight control and obesity prevention. Am J Obstet Gynecol. 2010;202(2):135.e1-8.

2. Oken E, Taveras EM, Kleinman KP, Rich-Edwards JW, Gillman MW. Gestational weight gain and child adiposity at age 3 years. Am J Obstet Gynecol. 2007;196(4):322.e1-8.

3. Oken E, Rifas-Shiman SL, Field AE, Frazier AL, Gillman MW. Maternal gestational weight gain and offspring weight in adolescence. Obstet Gynecol. 2008;112(5):999-1006.

4. Mamun AA, O'Callaghan M, Callaway L, Williams G, Najman J, Lawlor DA Associations of gestational weight gain with offspring body mass index and blood pressure at 21 years of age: evidence from a birth cohort study. Circulation. 2009;119(13):1720-7.

5. Gilmore LA, Klempel-Donchenko M, Redman LM. Pregnancy as a window to future health: excessive gestational weight gain and obesity. Semin Perinatol. 2015;39(4):296-303.

6. Deputy NP, Sharma AJ, Kim SY, Hinkle SN. Prevalence and characteristics associated with gestational weight gain adequacy. Obstet Gynecol. 2015; 125(4):773-81.

7. Muktabhant B, Lawrie TA, Lumbiganon P, Laopaiboon M. Diet or exercise, or both, for preventing excessive weight gain in pregnancy. Cochrane Database Syst Rev. 2015;6:CD007145.

8. Hill B, Skouteris H, Fuller-Tyszkiewicz M. Interventions designed to limit gestational weight gain: a systematic review of theory and meta-analysis of intervention components. Obes Rev. 2013;14(6):435-50.

9. Paul-Ebhohimhen $V$, Avenell A. A systematic review of the effectiveness of group versus individual treatments for adult obesity. Obes Facts. 2009;2:17-24.

10. Renjilian DA, Perri MG, Nezu AM, McKelvey WF, Shermer RL, Anton SD. Individual versus group therapy for obesity: effects of matching participants to their treatment preferences. J Consult Clin Psychol. 2001;69(4):717-21.
11. Carter EB, Temming LA, Akin J, Fowler S, Macones GA, Colditz GA, Tuuli MG. Group prenatal care compared with traditional prenatal care: a systematic review and meta-analysis. Obstet Gynecol. 2016;128(3):551-61.

12. Ruiz-Mirazo E, Lopez-Yarto M, McDonald SD. Group prenatal care versus individual prenatal care: a systematic review and meta-analyses. J Obstet Gynaecol Can. 2012;34:223-9.

13. Phelan S, Jankovitz K, Hagobian T, Abrams B. Reducing excessive gestational weight gain: lessons from the weight control literature and avenues for future research. Women's Health (Lond Engl). 2011;7(6):641-61.

14. Rising S. Centering pregnancy: an interdisciplinary model of empowerment J Nurs Midwifery. 1998;43:46-54.

15. Sheeder J, Weber Yorga K, Kabir-Greher K. A review of prenatal group care literature: the need for a structured theoretical framework and systematic evaluation. Matern Child Health J. 2012;16(1):177-87.

16. Institute of Medicine. Weight gain during pregnancy: reexamining the guidelines. In: 2009; Washington, DC; 2009.

17. Downs $\mathrm{SH}$, Black N. The feasibility of creating a checklist for the assessment of the methodological quality both of randomised and non-randomised studies of health care interventions. J Epidemiol Community Health. 1998;52(6):377-84

18. O'Connor SR, Tully MA, Ryan B, Bradley JM, Baxter GD, McDonough SM. Failure of a numerical quality assessment scale to identify potential risk of bias in a systematic review: a comparison study. BMC Res Notes. 2015;8:224.

19. Higgins JPT, Green S, editors. Cochrane handbook for systematic reviews of interventions version 5.1.0 [updated March 2011]: The Cochrane Collaboration; 2011. Available from http://handbook.cochrane.org

20. Moher D, Liberati A, Tetzlaff J, Altman DG, Group P. Preferred reporting items for systematic reviews and meta-analyses: the PRISMA statement. PLoS Med. 2009;6(7):e1000097.

21. Ickovics JR, Kershaw TS, Westdahl C, Magriples U, Massey Z, Reynolds H, Rising SS. Group prenatal care and perinatal outcomes: a randomized controlled trial. Obstet Gynecol. 2007;110:330-9.

22. Harden SM, Beauchamp MR, Pitts BH, Nault EM, Davy BM, You W, Weiss P, Estabrooks PA. Group-based lifestyle sessions for gestational weight gain management: a mixed method approach. Am J Health Behav. 2014;38(4):560-9.

23. Mazzoni SE, Hill PK, Webster KW, Heinrichs GA, Hoffman MC. Group prenatal care for women with gestational diabetes. J Matern Fetal Neonatal Med. 2016;29(17):2852-6.

24. Trotman G, Chhatre G, Darolia R, Tefera E, Damle L, Gomez-Lobo V. The effect of centering pregnancy versus traditional prenatal care models on improved adolescent health behaviors in the perinatal period. J Pediatr Adolesc Gynecol. 2015;28(5):395-401

25. Magriples U, Boynton MH, Kershaw TS, Lewis J, Rising SS, Tobin JN, Epel E, Ickovics JR. The impact of group prenatal care on pregnancy and postpartum weight trajectories. Am J Obstet Gynecol. 2015;213(5):688.e681-9.

26. Klima C, Norr K, Vonderheid S, Handler A. Introduction of CenteringPregnancy in a public health clinic. J Midwifery Womens Health. 2009;54:27-34.

27. Trudnak TE, Arboleda E, Kirby RS, Perrin K. Outcomes of Latina women in CenteringPregnancy group prenatal care compared with individual prenatal care. J Midwifery Womens Health. 2013;58(4):396-403.

28. Walton RB, Shaffer $\mathrm{S}$, Heaton J. Group prenatal care outcomes in a military population: a retrospective cohort study. Mil Med. 2015;180(7):825-9.

29. Kennedy HP, Farrell T, Paden R, Hill S, Jolivet RR, Cooper BA, Rising SS. A randomized clinical trial of group prenatal care in two military settings. Mil Med. 2011;176(10):1169-77.

30. Schellinger MM, Abernathy MP, Amerman B, May C, Foxlow LA, Carter AL, Barbour K, Luebbehusen E, Ayo K, Bastawros D, et al. Improved outcomes for Hispanic women with gestational Diabetes using the centering pregnancy(c) group prenatal care model. Matern Child Health J. 2017;21(2):297-305.

31. Holbrook HM: Exploring the Value of Group and Traditional Obstetrical Appointments to Reduce Health Disparity. 2010 Doctor of Nursing Practice (DNP) Projects. 4. https://repository.usfca.edu/dnp/4.

32. O'Donnell BE, Delapiana G, Wiener SR, Stotland NE, Gregorich S, Kuppermann M. Centering pregnancy prenatal care: a tool to decrease the risk of excessive gestational weight gain. Reprod Sci. 2016;23:276A.

33. Kominiarek MA, Crockett A, Covington-Kolb S, Simon M, Grobman WA. Association of group prenatal care with gestational weight gain. Obstet Gynecol. 2017;129:663-70.

34. Zielinski R, Stork L, Deibel M, Kothari C, Searing K. Improving infant and maternal health through CenteringPregnancy: a comparison of maternal health indicators and infant outcomes between women receiving group versus traditional prenatal care. Open J Obstet Gynecol. 2014;4:497-505. 
35. Tanner-Smith EE, Steinka-Fry KT, Gesell SB. Comparative effectiveness of group and individual prenatal care on gestational weight gain. Matern Child Health J. 2014;18(7):1711-20.

36. Brumley J, Cain MA, Stern M, Louis JM. Gestational weight gain and breastfeeding outcomes in group prenatal care. J Midwifery Womens Health. 2016;61(5):557-62.

37. Kominiarek MA, Peaceman AM. Gestational weight gain. Am J Obstet Gynecol. 2017;217(6):642-51.

38. Edelman D, McDuffie JR, Oddone E, Gierisch JM, Nagi A, Williams JW Jr. Shared medical appointments for chronic medical conditions: a systematic review. Washington (DC): Department of Veterans Affairs; 2012.

39. Burke RE, O'Grady ET. Group visits hold great potential for improving diabetes care and outcomes, but best practices must be developed. Health Aff (Millwood). 2012;31(1):103-9.

40. Clancy DE, Brown SB, Magruder KM, Huang P. Group visits in medically and economically disadvantaged patients with type 2 diabetes and their relationships to clinical outcomes. Top Health Inf Manag. 2003;24(1):8-14.

41. Stead LF, Lancaster T. Group behaviour therapy programmes for smoking cessation. Cochrane Database Syst Rev. 2000;2:CD001007.

42. Knowler WC, Barrett-Connor E, Fowler SE, Hamman RF, Lachin JM, Walker EA, Nathan DM, Diabetes Prevention Program Research G. Reduction in the incidence of type 2 diabetes with lifestyle intervention or metformin. N Engl J Med. 2002;346(6):393-403.

43. Brokaw SM, Arave D, Emerson DN, Butcher MK, Helgerson SD, Harwell TS, Montana Cardiovascular D, Diabetes Prevention W. Intensive lifestyle intervention goals can be achieved as effectively with large groups as with small groups. Prim Care Diabetes. 2014;8(4):295-300.

44. Heshka S, Anderson JW, Atkinson RL, Greenway FL, Hill JO, Phinney SD, Kolotkin RL, Miller-Kovach K, Pi-Sunyer FX. Weight loss with self-help compared with a structured commercial program: a randomized trial. JAMA. 2003:289:1792-8

45. Tsai AG, Wadden TA. Systematic review: an evaluation of major commercial weight loss programs in the United States. Ann Intern Med. 2005;142:56-66.

46. Wolfe W. A review: maximizing social support--a neglected strategy for improving weight management with African-American women. Ethn Dis. 2004; 14:212-8

47. Black DR, Gleser LJ, Kooyers KJ. A meta-analytic evaluation of couples weight-loss programs. Health Psychol. 1990;9(3):330-47.

48. Kotelchuck M. An evaluation of the Kessner adequacy of prenatal care index and a proposed adequacy of prenatal care utilization index. Am J Public Health. 1994:84(9):1414-20.

Ready to submit your research? Choose BMC and benefit from:

- fast, convenient online submission

- thorough peer review by experienced researchers in your field

- rapid publication on acceptance

- support for research data, including large and complex data types

- gold Open Access which fosters wider collaboration and increased citations

- maximum visibility for your research: over $100 \mathrm{M}$ website views per year

At BMC, research is always in progress.

Learn more biomedcentral.com/submissions 